\title{
Finite element modeling of superplastic co-doped yttria-stabilized tetragonal-zirconia polycrystals
}

\author{
Hsuan-Teh HU ${ }^{\dagger 1}$, Shih-Tsung TSENG ${ }^{1}$, Alice $\mathrm{HU}^{2}$ \\ ('Department of Civil Engineering, National Cheng Kung University, Tainan 701, China) \\ ( ${ }^{2}$ Department of Mechanical and Biomedical Engineering, City University of Hong Kong, Hong Kong, China) \\ †E-mail: hthu@mail.ncku.edu.tw \\ Received May 30, 2015; Revision accepted May 10, 2016; Crosschecked Nov. 11, 2016
}

\begin{abstract}
Yttria-stabilized tetragonal-zirconia polycrystals (Y-TZP) have been shown to have superplastic properties at high temperatures, opening a way for the manufacture of complex pieces for industrial applications by a variety of techniques. However, before that is possible, it is important to analyze the deformation and fracture mechanisms at a macroscopic level based on continuum theory. In this paper, an elastic-plastic material model with a theoretical large deformation is constructed to simulate the true stress-true strain relationships of superplastic ceramics. The simplified constitutive law used for the numerical simulations is based on piecewise linear connections at the turning points of different deformation stages on the experimental stressstrain curves. The finite element model (FEM) is applied to selected tensile tests on 3-mol\%-Y-TZP (3Y-TZP) co-doped with germanium oxide and other oxides (titanium, magnesium, and calcium) to verify its applicability. The results show that the stress-strain characteristics and the final deformed shapes in the finite element analysis (FEA) agree well with the tensile test experiments. It can be seen that the FEM presented can simulate the mechanical behavior of superplastic co-doped 3Y-TZP ceramics and that it offers a selective numerical simulation method for advanced development of superplastic ceramics.
\end{abstract}

Key words: Finite element analysis (FEA), $\mathrm{Y}_{2} \mathrm{O}_{3}$-stabilized tetragonal-zirconia polycrystals (Y-TZP), Superplasticity http://dx.doi.org/10.1631/jzus.A1500159

CLC number: O34

\section{Introduction}

Ceramics have several excellent properties that are unique among materials. They are extremely hard, have good resistance to fatigue, abrasion, and chemical corrosion, and are resistant to erosion at high temperatures. Hence, ceramics can be used in extreme environments, and their applications are extensive in both household and industrial products. However, they have a fatal weakness, brittleness, which means that they break at small levels of strain and cannot withstand extensive elongation under load. Thus, there has been a significant research effort to reduce the brittleness of ceramics.

(i) ORCID: Hsuan-Teh HU, http://orcid.org/0000-0001-8582-0670 C Zhejiang University and Springer-Verlag Berlin Heidelberg 2016
Through the tailoring of very refined particles, tetragonal-zirconia polycrystals (TZP) retain a metastable tetragonal phase at room temperature and have been shown to have excellent plastic properties (Garvie et al., 1975). Wakai et al. (1986) demonstrated that a $3 \%$ (mole concentration, the same meaning unless otherwise stated) $\mathrm{Y}_{2} \mathrm{O}_{3}$-stabilized TZP (3Y-TZP) with an average grain size smaller than $0.3 \mu \mathrm{m}$ could be elongated superplastically to greater than $120 \%$ of the nominal strain under conditions of constant strain rates ranging from $1.1 \times 10^{-4} \mathrm{~s}^{-1}$ to $5.5 \times 10^{-4} \mathrm{~s}^{-1}$ at a temperature of $1450{ }^{\circ} \mathrm{C}$. It was the research that first revealed the superplasticity of 3 Y-TZP. Since then, much effort has been devoted to the development of ceramics with improved superplasticity. Jiménez-Melendo et al. (1998) analyzed extensive experimental data for fine-grained $\mathrm{Y}_{2} \mathrm{O}_{3}$-stabilized $\mathrm{ZrO}_{2}$ polycrystals 
(Y-SZP) containing 2\%-4\% $\quad \mathrm{Y}_{2} \mathrm{O}_{3}$. The analyses were performed as a function of stress, grain size, and material purity at temperatures between $1250{ }^{\circ} \mathrm{C}$ and $1450{ }^{\circ} \mathrm{C}$. It was concluded that for high-purity Y-SZP (impurity content less than $10 \%$ in weight), the constitutive equation for superplastic flow in region II (the high-stress region) was similar to that for superplastic metallic materials. On the other hand, it was determined that the equation for region I (the low-stress region) should be formulated by incorporating a threshold stress approach. However, the stress-strain relationships for low-purity Y-SZP (impurity content greater than $0.10 \%$ in weight) were different from those of metallic systems (JiménezMelendo et al., 1998; Jiménez-Melendo and Domínguez-Rodríguez 1999). It was not possible to model the behavior of ceramics with a highly viscous liquid phase by using the metallic constitutive creep models relevant to a steady-state strain rate at high temperatures (Bieler et al., 1996). Wakai et al. (1999) noted that there existed no model that could explain all the experimental data on Y-TZP deformation mechanisms. Currently, in a deep analysis of the multi-scale (macroscopic) nature of ceramic superplasticity, one of the major goals that has to be fulfilled is correlation between the behavior of one individual grain under shear and normal stresses and their average collective behavior (DomínguezRodríguez and Gómez-García, 2010).

Combining the superplastic properties of ceramics with processing techniques, such as sheet formation, blowing, stamping, forging, and spinning, would support the industrial manufacture of complex ceramic pieces for applications in aerospace, defense, and automobile manufacturing, among others (Domínguez-Rodríguez and Gómez-García, 2010). However, before that is practical, we must gain more understanding of superplastic ceramics in respect of mechanical stress distribution and fracture mechanisms at a macroscopic level when the materials deform. So here we intend, by means of solid mechanics or plasticity theory, to provide further analysis of the deformation progress of superplastic ceramics so that uses of this kind of material may be developed on the basis of safe designs.

A great deal of research on the finite element analysis (FEA) of superplastic forming (SPF) processes has been published. However, most of this research has been focused on metallic materials such as titanium-based, aluminum-based, zinc-based, copper-based, and magnesium-based alloys. These finite element models (FEMs) have included combinations of several simulation conditions, which can generally be classified into different dimensions (2D or 3D) with different constitutive models (elasticplastic, rigid-plastic, elastic-viscoplastic, or rigidviscoplastic); some of these models have included the microstructure evolution of grain growth or void growth to regulate the stress-strain relationships of various materials, different elements, and the assumption of isotropic or anisotropic material properties, among other considerations. For example, Wang and Budiansky (1978) and Hsu and Chu (1995) used membrane elements, and Hsu and Shien (1997) used shell elements in a 2D condition to simulate the sheet metal stamping process; in addition, their FEM contained an elastic-plastic constitutive model for which post-yield anisotropic material behavior was formulated by the flow rule associated with Hill's quadratic yield criterion. Lee and Kobayash (1973) simulated superplastic metal formation problems by using $2 \mathrm{D}$ shell elements with a rigidplastic constitutive model which was related to the associated flow rule with the von Mises quadratic yield criterion for isotropic materials, or with Hill's in the case of anisotropic materials. On the other hand, Zienkiewicz and Godbole (1974), Kim et al. (1996), El-Morsy et al. (2001), Liew et al. (2003), and Giuliano (2005; 2006) simulated superplastic alloys as non-Newtonian viscous flow materials with a rigid-viscoplastic constitutive model to study SPF problems. Among these, Liew et al. (2003) combined both grain growth and void growth evolutions within the model to incorporate the effect of the strain rate. On the other hand, Kim et al. (1996) combined a strain rate controlling function in their model that could control the pressure to maintain the maximum strain rate near a target value during analysis and obtain the optimal pressure-time relationships for the SPF process under the prerequisite that the material did not crack. Similarly, for research on SPF problems that simulate superplastic alloys as non-Newtonian viscous flow materials using an elastic-viscoplastic constitutive model, Chandra (1988) and Nazzal et al. (2011) incorporated grain growth evolution; Abu-Farha and Khraisheh (2007) incorporated both grain and void growth evolutions; Chen et al. (2001), Hassan et al. (2003), Li et al. 
(2004), and Yenihayat et al. (2005) combined the strain rate controlling capability, and Ding et al., (1995), Huh et al. (1995), Lin (2003), Nazzal et al. (2004), Tao and Keavey (2004), and Nazzal and Khraisheh (2008) joined microstructure evolutions and the strain rate controlling capability together within their models.

To date, FEA on superplastic problems has been done almost exclusively for metallic alloys, and there has been comparatively little FEA on superplastic ceramics. Since the basic properties of chemical bonding in metals and ceramics are different, the superplastic deformation mechanisms of these two kinds of materials are not the same. A total stressstrain history of superplastic deformation includes the low-stress and high-stress regions of the sigmoidal creep behavior as represented by a double logarithmic strain rate vs. stress axes, and therefore the constitutive characteristics of superplastic metals and ceramics are different from each other. Hence, a precise numerical simulation of a complete stressstrain progress is very important for subsequent mechanically-based analysis, for example, the simulation of fracture mechanisms and the development of safe design specifications. The aim of this study is to construct a numerical FEM to simulate the stressstrain progress of co-doped 3Y-TZP ceramics based on the continuum theory of plasticity. The constitutive model here embedded in the FEM is an elasticplastic model that formulates the elastic behavior using Hooke's law and the subsequent work hardening behavior by combining the associated von Mises flow rule with the isotropic hardening rule.

\section{Geometry of experimental samples}

The presented FEM was verified with the tensile test experiments performed by Sasaki et al. (2001) on co-doped 3Y-TZP ceramics. In the experiments, commercially available high-purity $3 \mathrm{Y}$-TZP powders were used as the base material, and the dopants were germanium oxide, titanium oxide, calcium oxide, and magnesium oxide in the following compositions: $2 \%$ (mole concentration) $\mathrm{Ge}, 1 \% \mathrm{Mg}$ $(2 \mathrm{Ge}-1 \mathrm{Mg}) ; 2 \% \mathrm{Ge}, 1 \% \mathrm{Ca}(2 \mathrm{Ge}-1 \mathrm{Ca}) ;$ and $2 \% \mathrm{Ge}$, $2 \% \mathrm{Ti}(2 \mathrm{Ge}-2 \mathrm{Ti})$. The mixed powders were manufactured into specimens of a theoretical density greater than $95 \%$ through processes of ball milling, drying, sieving, pressing, and sintering. Then the specimens were trimmed into the shape of a dog bone for the tensile test samples, whose middle gauge region had an approximate cross section of $2 \mathrm{~mm} \times 2 \mathrm{~mm}$ and a length of $13.4 \mathrm{~mm}$. The tensile tests were conducted at a temperature of $1400{ }^{\circ} \mathrm{C}$ under a quasi-static strain control condition. The stress-strain characteristics of the experimental results are shown in Fig. 1, and the corresponding final deformed shapes are depicted in Fig. 2.

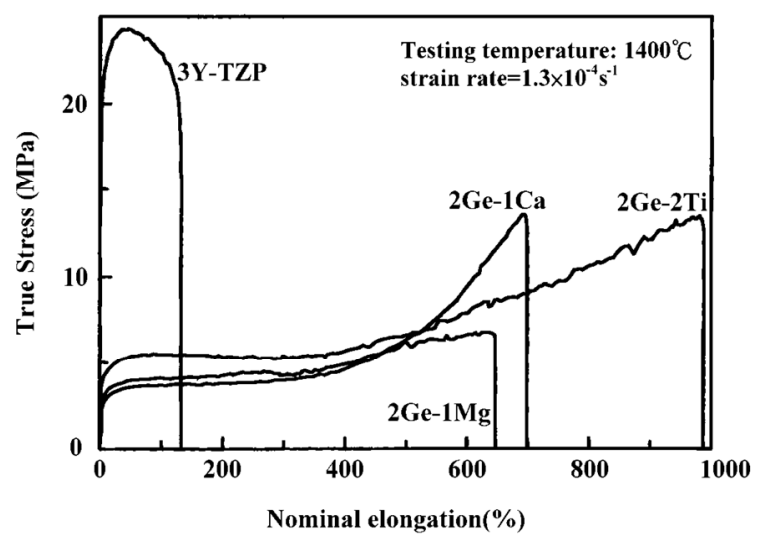

Fig. 1 Stress-strain characteristics of tensile tests for 3YTZP and three co-doped materials (Sasaki et al., 2001)

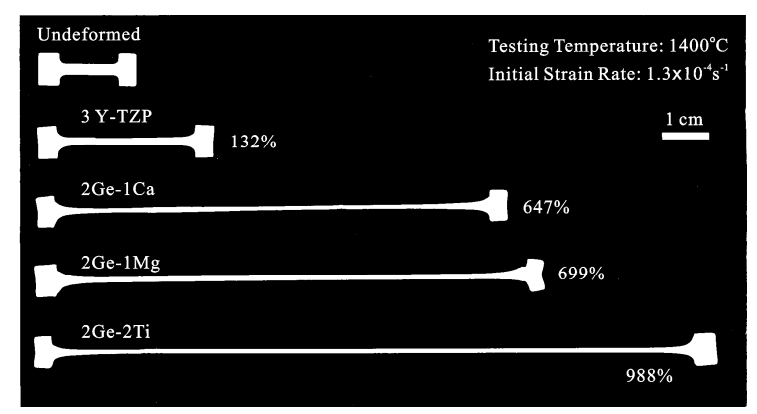

Fig. 2 Photograph of deformed tensile samples for 3YTZP and three co-doped materials

Figs. 1 and 2 are reprinted from (Sasaki et al., 2001), Copyright 2001, with permission from John Wiley and Sons

The experiments showed the co-doped 3Y-TZP had excellent superplastic properties, with the largest nominal strain of $988 \%$ in the $2 \mathrm{Ge}-2 \mathrm{Ti}$ composition. Furthermore, as indicated from an inspection using scanning electron microscopy (SEM), all samples consisted of a homogeneous and equiaxed microstructure, and no amorphous phases were found (Sasaki et al., 2001). Hence, they could be regarded as 
homogeneous and isotropic materials at the macroscopic scale. The average grain sizes of the four compositions were: $3 \mathrm{Y}-\mathrm{TZP}, 0.38 \mu \mathrm{m} ; 2 \mathrm{Ge}-1 \mathrm{Mg}$, $0.44 \mu \mathrm{m} ; 2 \mathrm{Ge}-1 \mathrm{Ca}, 0.55 \mu \mathrm{m} ; 2 \mathrm{Ge}-2 \mathrm{Ti}, 0.51 \mu \mathrm{m}$.

\section{Constitutive equations}

In this study, we assumed the superplastic codoped 3Y-TZP ceramics to be homogeneous and isotropic. The chosen constitutive model embedded in the present FEM was an elastic-plastic model. The elastic behavior was formulated using Hooke's law, and the work hardening plastic stress-strain relationships were derived by combining the flow rule associated with the von Mises quadratic yield criterion with the isotropic hardening rule. According to the theory of plasticity, the relative equations of the elastic-plastic model can be derived as follows (Chen and Han, 2007).

The total strain increment is decomposed into two parts,

$$
\mathrm{d} \varepsilon_{i j}=\mathrm{d} \varepsilon_{i j}^{\mathrm{e}}+\mathrm{d} \varepsilon_{i j}^{\mathrm{p}},
$$

where the elastic strain increment, $\mathrm{d} \varepsilon_{i j}^{\mathrm{e}}$, is related to the stress increment, $\mathrm{d} \sigma_{i j}$, by Hooke's law as

$$
\mathrm{d} \sigma_{i j}=C_{i j k l} \mathrm{~d} \varepsilon_{k l}^{\mathrm{e}},
$$

where $\boldsymbol{C}_{i j k l}$ is the tensor of elastic modulus. For a linear-elastic isotropic material, $\boldsymbol{C}_{i j k l}$ can be expressed in terms of the two elastic constants, shear modulus $G$ and Poisson's ratio $v$ :

$$
\boldsymbol{C}_{i j k l}=2 G\left(\boldsymbol{\delta}_{i k} \boldsymbol{\delta}_{j l}+\frac{v}{1-2 v} \boldsymbol{\delta}_{i j} \boldsymbol{\delta}_{k l}\right),
$$

where $\boldsymbol{\delta}_{i j}$ is the Kronecker delta.

The plastic strain increment, $\mathrm{d} \varepsilon_{i j}^{\mathrm{p}}$, can be generally expressed by a non-associated flow rule in the form of

$$
\mathrm{d} \varepsilon_{i j}^{\mathrm{p}}=\mathrm{d} \lambda \frac{\partial g}{\partial \sigma_{i j}},
$$

where $\mathrm{d} \lambda$ is a positive scalar factor of proportionality, which is non-zero only when plastic deformations occur, and $g$ is known as the plastic potential function. The equation $g\left(\sigma_{i j}, \varepsilon_{i j}^{\mathrm{p}}, k\right)=$ constant defines a surface of plastic potential in a 9D stress space. When the yield function and the plastic potential function coincide, $f=g$, the plastic flow equations can be expressed as

$$
\mathrm{d} \varepsilon_{i j}^{\mathrm{p}}=\mathrm{d} \lambda \frac{\partial f}{\partial \boldsymbol{\sigma}_{i j}} .
$$

Eq. (5) is called the associated flow rule because the plastic flow is associated with the yield criterion. The loading surface, which defines the boundary of the current elastic region, is the subsequent yield surface for an elastoplastically deformed material under combined states of stress, and it can generally be written as

$$
f\left(\sigma_{i j}, \varepsilon_{i j}^{\mathrm{p}}, k\right)=F\left(\sigma_{i j}, \varepsilon_{i j}^{\mathrm{p}}\right)-k^{2}\left(\varepsilon_{\mathrm{p}}\right)=0 .
$$

The size of the yield surface is governed by the hardening parameter $k^{2}$ expressed as a function of $\varepsilon_{\mathrm{p}}$, called the effective strain. Hence, the parameter $k^{2}$ depends upon the plastic strain history. The function $F\left(\sigma_{i j}, \varepsilon_{i j}^{\mathrm{p}}\right)$ defines the shape of the yield surface. Moreover, for a work-hardening material, the hardening rule is necessary to describe the rule for the evolution of the loading surface. Since we assumed the analyzed material to be isotropic, we took the von Mises yield function as the plastic potential and the isotropic hardening rule, which expanded the initial yield surface uniformly without distortion and translation, as the evolution of the loading surface. When the von Mises yield criterion is used, we can obtain

$$
F\left(\sigma_{i j}, \varepsilon_{i j}^{\mathrm{p}}\right)=J_{2},
$$

with $J_{2}$ expressed in the following as the invariant of the stress deviator tensor:

$$
J_{2}=\frac{1}{2} \boldsymbol{s}_{i j} \boldsymbol{s}_{i j}
$$

where $\boldsymbol{s}_{i j}$ denotes the stress deviator tensor defined 
by subtracting the spherical state of stress from the actual state of stress.

$$
\boldsymbol{s}_{i j}=\boldsymbol{\sigma}_{i j}-\frac{1}{3} \boldsymbol{\sigma}_{k k} \boldsymbol{\delta}_{i j} .
$$

Then Eq. (6) becomes

$$
f\left(\boldsymbol{\sigma}_{i j}, \boldsymbol{\varepsilon}_{i j}^{\mathrm{p}}, k\right)=\frac{1}{2} \boldsymbol{s}_{i j} \boldsymbol{s}_{i j}-k^{2}\left(\varepsilon_{\mathrm{p}}\right)=0 .
$$

For practical use of the work-hardening theory of plasticity, the hardening parameters in the loading function have to be related to the experimental uniaxial stress-strain curve. To this end, the stress variable $\sigma_{\mathrm{e}}$, called the effective stress, and the strain variable $\varepsilon_{\mathrm{p}}$, called the effective strain, are introduced. Since the effective stress should reduce to the stress $\sigma_{1}$ in the uniaxial test, it follows that the loading function $F\left(\sigma_{i j}\right)$ can be expressed as $F\left(\sigma_{i j}\right)=C \sigma_{\mathrm{e}}^{n}$, where $C$ and $n$ are constants. For a von Mises material, $F\left(\sigma_{i j}, \varepsilon_{i j}^{\mathrm{p}}\right)=J_{2}$, then

$$
J_{2}=C \sigma_{\mathrm{e}}^{n}
$$

and for the uniaxial test, $\sigma_{\mathrm{e}}=\sigma_{1}$ and $\sigma_{2}=\sigma_{3}=0$, where $\sigma_{1}, \sigma_{2}$, and $\sigma_{3}$ are principal stresses. Therefore, $n=2$, $C=1 / 3$, and

$$
\sigma_{\mathrm{e}}=\sqrt{3 J_{2}}=\sqrt{\frac{3}{2} s_{i j} \boldsymbol{s}_{i j}} .
$$

To replace the hardening parameter $k$ with $\sigma_{\mathrm{e}}$, we substitute Eq. (12) into Eq. (10) and rewrite it as

$$
f\left(\sigma_{i j}, \varepsilon_{i j}^{\mathrm{p}}, k\right)=\frac{3}{2} \boldsymbol{s}_{i j} \boldsymbol{s}_{i j}-\sigma_{\mathrm{e}}^{2}\left(\varepsilon_{\mathrm{p}}\right)=0 .
$$

From the definition of the associated flow rule, $g=f$, the derivatives of $g$ and $f$ are found as

$$
\frac{\partial f}{\partial \sigma_{i j}}=\frac{\partial g}{\partial \sigma_{i j}}=3 s_{i j} .
$$

Then Eq. (5) becomes $\mathrm{d} \varepsilon_{i j}^{\mathrm{p}}=\mathrm{d} \lambda\left(3 s_{i j}\right)$, where $\mathrm{d} \lambda$ is a scalar function to be determined by the con- sistency condition $\mathrm{d} f=0$ as

$$
\mathrm{d} \lambda=\frac{1}{h} \frac{\partial f}{\partial \sigma_{i j}} \boldsymbol{C}_{i j k l} \mathrm{~d} \boldsymbol{\varepsilon}_{k l}=\frac{1}{h} \boldsymbol{H}_{k l} \mathrm{~d} \boldsymbol{\varepsilon}_{k l},
$$

with

$$
h=4\left(3 G+H_{\mathrm{p}}\right) \sigma_{\mathrm{e}}^{2},
$$

where the second-order tensor $\boldsymbol{H}_{k l}$ associated with the yield function $f$ is defined as

$$
\boldsymbol{H}_{k l}=\frac{\partial f}{\partial \boldsymbol{\sigma}_{i j}} \boldsymbol{C}_{i j k l}=6 G \boldsymbol{s}_{k l} .
$$

The parameter $H_{\mathrm{p}}$ is a plastic modulus associated with the rate of expansion of the loading surface, and it can be defined as the slope of the uniaxial stressplastic strain curve at the current value of $\sigma_{\mathrm{e}}$ :

$$
H_{\mathrm{p}}=\frac{\mathrm{d} \sigma_{\mathrm{e}}}{\mathrm{d} \varepsilon_{\mathrm{p}}}
$$

For the $F\left(J_{2}, J_{3}\right)$ material, such as the von Mises material, which is pressure independent when plastic flow occurs, the effective plastic strain increment is defined as

$$
\mathrm{d} \varepsilon_{\mathrm{p}}=\sqrt{\frac{2}{3} \mathrm{~d} \varepsilon_{i j}^{\mathrm{p}} \mathrm{d} \varepsilon_{i j}^{\mathrm{p}}}
$$

The strain history for the material is the record of the length of the effective plastic strain path:

$$
\varepsilon_{\mathrm{p}}=\int \mathrm{d} \varepsilon_{\mathrm{p}}=\int \frac{\mathrm{d} \sigma_{\mathrm{e}}}{H_{\mathrm{p}}\left(\sigma_{\mathrm{e}}\right)}
$$

From the above equations, when the plastic flow occurs, the constitutive law of stress-strain relationships can be derived as

$$
\begin{aligned}
\mathrm{d} \boldsymbol{\sigma}_{i j} & =\boldsymbol{C}_{i j k l} \mathrm{~d} \boldsymbol{\varepsilon}_{k l}^{\mathrm{e}}=\boldsymbol{C}_{i j k l}\left(\mathrm{~d} \boldsymbol{\varepsilon}_{k l}-\mathrm{d} \boldsymbol{\varepsilon}_{k l}^{\mathrm{p}}\right) \\
& =\boldsymbol{C}_{i j k l}\left(\mathrm{~d} \boldsymbol{\varepsilon}_{k l}-\mathrm{d} \lambda \frac{\partial f}{\partial \boldsymbol{\sigma}_{k l}}\right) \\
& =\boldsymbol{C}_{i j k l}\left(\mathrm{~d} \boldsymbol{\varepsilon}_{k l}-\frac{1}{h} \frac{\partial f}{\partial \boldsymbol{\sigma}_{m n}} \boldsymbol{C}_{m n s t} \frac{\partial f}{\partial \boldsymbol{\sigma}_{k l}} \mathrm{~d} \boldsymbol{\varepsilon}_{s t}\right)
\end{aligned}
$$




$$
\begin{aligned}
& =\boldsymbol{C}_{i j k l}\left(\boldsymbol{\delta}_{s k} \boldsymbol{\delta}_{t l}-\frac{1}{h} \frac{\partial f}{\partial \boldsymbol{\sigma}_{m n}} \boldsymbol{C}_{m n s t} \frac{\partial f}{\partial \boldsymbol{\sigma}_{k l}}\right) \mathrm{d} \boldsymbol{\varepsilon}_{s t} \\
& =\left(\boldsymbol{C}_{i j s t}-\frac{1}{h} \frac{\partial f}{\partial \boldsymbol{\sigma}_{m n}} \boldsymbol{C}_{m n s t} \boldsymbol{C}_{i j k l} \frac{\partial f}{\partial \boldsymbol{\sigma}_{k l}}\right) \mathrm{d} \boldsymbol{\varepsilon}_{s t} \\
& =\left(\boldsymbol{C}_{i j s t}-\frac{1}{h} \boldsymbol{H}_{s t} \boldsymbol{H}_{i j}\right) \mathrm{d} \boldsymbol{\varepsilon}_{s t} .
\end{aligned}
$$

Hence,

$$
\begin{aligned}
\mathrm{d} \boldsymbol{\sigma}_{i j} & =\boldsymbol{C}_{i j k l}^{\mathrm{ep}} \mathrm{d} \boldsymbol{\varepsilon}_{k l}=\left(\boldsymbol{C}_{i j k l}+\boldsymbol{C}_{i j k l}^{\mathrm{p}}\right) \mathrm{d} \boldsymbol{\varepsilon}_{k l} \\
& =\left(\boldsymbol{C}_{i j k l}-\frac{1}{h} \boldsymbol{H}_{i j} \boldsymbol{H}_{k l}\right) \mathrm{d} \boldsymbol{\varepsilon}_{k l} \\
& =\left(\boldsymbol{C}_{i j k l}-\frac{36 G^{2}}{h} \boldsymbol{s}_{i j} \boldsymbol{s}_{k l}\right) \mathrm{d} \boldsymbol{\varepsilon}_{k l},
\end{aligned}
$$

and

$$
\boldsymbol{C}_{i j k l}^{\mathrm{ep}}=\boldsymbol{C}_{i j k l}+\boldsymbol{C}_{i j k l}^{\mathrm{p}}
$$

with

$$
\boldsymbol{C}_{i j k l}^{\mathrm{p}}=-\frac{1}{h} \boldsymbol{H}_{i j} \boldsymbol{H}_{k l}=-\frac{36 G^{2}}{h} \boldsymbol{s}_{i j} \boldsymbol{s}_{k l} .
$$

In conclusion, the complete stress-strain relationships for an elastic-plastic work-hardening material can be expressed as follows:

1. When $f\left(\sigma_{i j}, \varepsilon_{i j}^{\mathrm{p}}, k\right)=0$ with $\mathrm{d} \lambda>0$, the material is in a plastic loading state. We have $\mathrm{d} \sigma_{i j}=C_{i j k l}^{\mathrm{ep}} \mathrm{d} \boldsymbol{\varepsilon}_{k l}$, where $\boldsymbol{C}_{i j k l}^{\mathrm{ep}}$ is given in Eqs. (22) and (23).

2. When $f\left(\sigma_{i j}, \varepsilon_{i j}^{\mathrm{p}}, k\right)<0$ or $f\left(\sigma_{i j}, \varepsilon_{i j}^{\mathrm{p}}, k\right)=0$ with $\mathrm{d} \lambda \leq 0$, the material is in an unloading or neutral loading state. We have $\mathrm{d} \boldsymbol{\sigma}_{i j}=\boldsymbol{C}_{i j k l} \mathrm{~d} \boldsymbol{\varepsilon}_{k l}$, where $\boldsymbol{C}_{i j k l}$ is given in Eq. (3).

\section{Finite element analysis}

Calculations were carried out by means of the finite element (FE) method in this study, and the results were verified by the uniaxial tensile experiments conducted by Sasaki et al. (2001) on 3Y-TZP, $2 \mathrm{Ge}-1 \mathrm{Mg}, 2 \mathrm{Ge}-1 \mathrm{Ca}$, and $2 \mathrm{Ge}-2 \mathrm{Ti}$ superplastic ceramics. The FE simulation was performed using a commercial FE package, Abaqus (Dassault Systèmes Corporation, 2014). The elastic-plastic constitutive model used in this study was an Abaqus built-in metal plasticity material model, in which the isotropic hardening rule could be included. The experimental constitutive stress-strain hardening data could be defined in tabular form as the input for the metal plasticity material model in Abaqus. When the analysis begins, Abaqus connects the data points with piecewise linear line segments to approximate the nonlinear stress-strain relationships of materials. It is unnecessary to input all of the experimental stressstrain data because if a simplified material constitutive law is used in an FEM, which can simulate the major stages of deformation without losing the accuracy between the FEA and the experimental results, then it can be regarded as a practical one for the purpose of applications. Therefore, in this study, a simplified constitutive law was created based on the following rule: the turning points for different deformation stages of the experimental stress-strain curves have piecewise linear connections. According to this rule, there were three to four data points chosen for every studied composition, and the simplified constitutive laws used in Abaqus for the FE simulations are shown in Fig. 3. Although these input data seem to simplify by following the complete experimental stress-strain characteristics, the FEA of superplastic deformation problems may be aborted before reaching the experimental ultimate fracture strain as it will lead to numerical errors for various reasons. For instance, (1) extreme superplastic deformation will lead to an increase of element aspect ratios which usually are accompanied by cumulative numerical errors and distortion of the mesh; (2) suddenly changed material properties or geometric shapes at some regions exhibiting stress concentrations may result in singular points, which will increase the difficulty of numerical convergence or lead to severe local deformation in a few elements; (3) strain-hardening or strain-softening material properties will also result in FE calculations becoming more difficult to converge. Therefore, in this study, we incorporate the above-mentioned simplified constitutive laws with the following adequate FE model, and thus expect to maintain accuracy between numerical and experimental results at any deformation stage until reaching the experimental ultimate fracture strain, without aborting due to numerical errors or local distortions occurring in the model. 
Note that the curves in Fig. 3 are recorded as true stresses vs. nominal strains (or engineering strains) from experimental data. In order to simulate the large deformation of the superplastic materials for FEA, those true stress-nominal strain curves are transformed into true stress-true strain curves and input to the Abaqus program. Let $\varepsilon_{\text {nom }}$ be the nominal strain and $\varepsilon_{\text {true }}$ be the true strain. The transformation equation between these two strains can be written as

$$
\varepsilon_{\text {true }}=\ln \left(1+\varepsilon_{\text {nom }}\right) .
$$

In the present analyses, the stress concentration caused the greatest elongation to occur at only a few elements on the junction of the outside clamping region and the middle gauge region of the bone samples. To avoid this, the geometry of the studied cases introduced in Section 2 is schematized in Fig. 4, which only includes a gauge region with a cross section of $2 \mathrm{~mm} \times 2 \mathrm{~mm}$ and a length of $13.4 \mathrm{~mm}$.

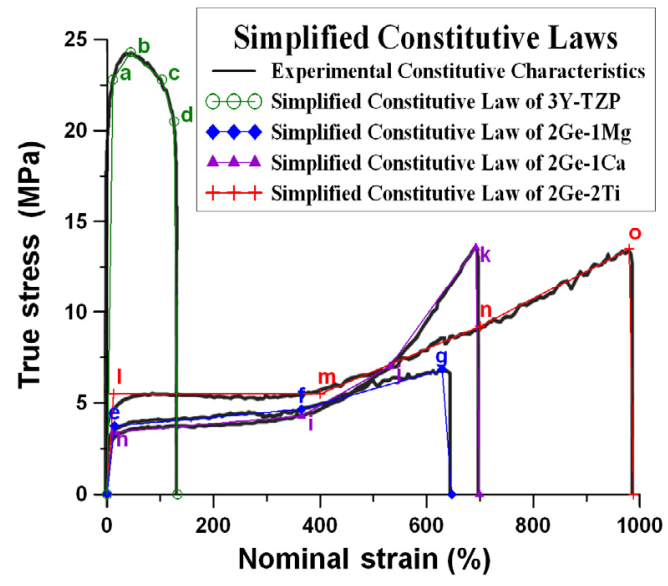

Fig. 3 Simplified constitutive laws of 3Y-TZP and three co-doped materials

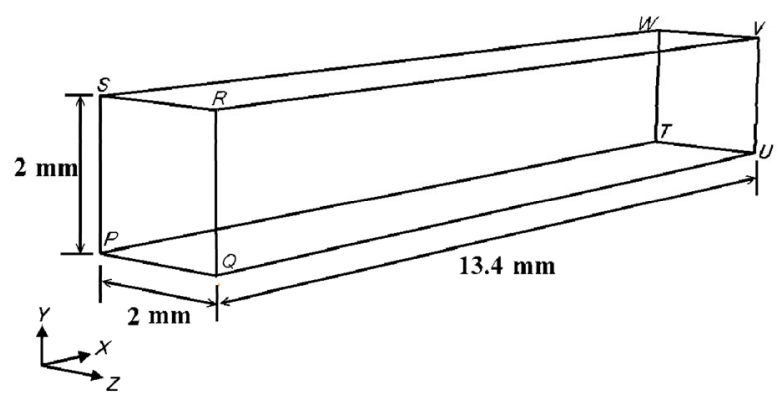

Fig. 4 Geometry of the FEM
The analyses were conducted with a 3D simulation with the advantage of being able to clearly examine the stress and deformation conditions in the model. For the purpose of simulating the uniaxial tensile test with a strain control technique, the boundary and loading conditions are shown in Fig. 5 and are described as follows: $u_{x}=0$ is applied to the $P Q R S$ plane; $u_{y}=0$ is applied to the $P Q$ and $T U$ line segments; $u_{z}=0$ is applied to the $P$ and $T$ points; a uniform deformation $u_{x}=0.15 \mathrm{~m}$ is applied to the $T U V W$ plane. The element used in the analysis is the 3D solid (continuum) element, C3D20, which has 20 nodes with three degrees of freedom per node (displacements in the $x, y$, and $z$ directions). The finite element mesh of the specimen is shown in Fig. 6. The cases studied here addressed the problem of a homogeneous and isotropic material experiencing uniform uniaxial loading on its uniform cross section. According to the theory of continuum mechanics, the internal axial stresses and strains existing in elements throughout the model should be uniformly distributed; thus, there is no need to perform a convergent analysis on the element numbers of the model. However, we observed that the aspect ratio of elements should be less than a maximum value of 4 to avoid a numerical error in the FE calculation. By arranging the numbers of the elements equal to 7,1 ,

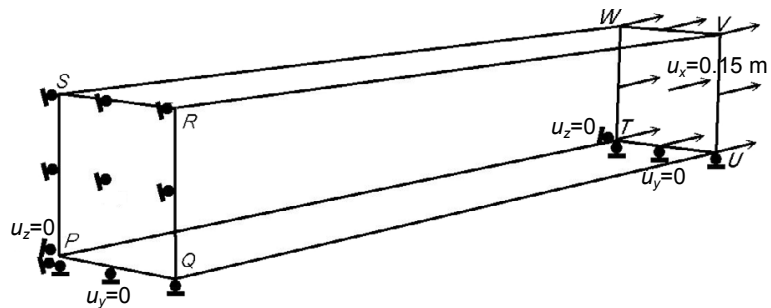
$\stackrel{Y}{\longrightarrow} x$

Fig. 5 Boundary conditions of the FEM

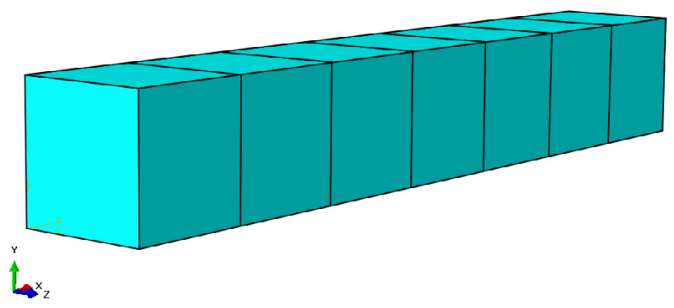

Fig. 6 Element distribution of the FEM 
and 1 corresponding to the $x, y$, and $z$ directions, respectively, the aspect ratio of the elements in the model was 1.04 .

\section{Results and discussion}

The comparison of true stress vs. nominal strain relationships between the experimental results and numerical analysis for the four studied compositions is presented in Fig. 7. Regardless of whether the brittle $3 \mathrm{Y}$-TZP or the comparatively superplastic $2 \mathrm{Ge}-$ $1 \mathrm{Mg}, 2 \mathrm{Ge}-1 \mathrm{Ca}$, and $2 \mathrm{Ge}-2 \mathrm{Ti}$ ceramics were examined, this figure shows that the experimental stressstrain relationships were in good agreement with the FEA results for any stage of deformation: elastic loading, horizontal plastic stretch, strain hardening, and strain softening until ultimate fracture. The original undeformed and the final deformed shapes of the FEA for the four compositions are depicted in Fig. 8 .

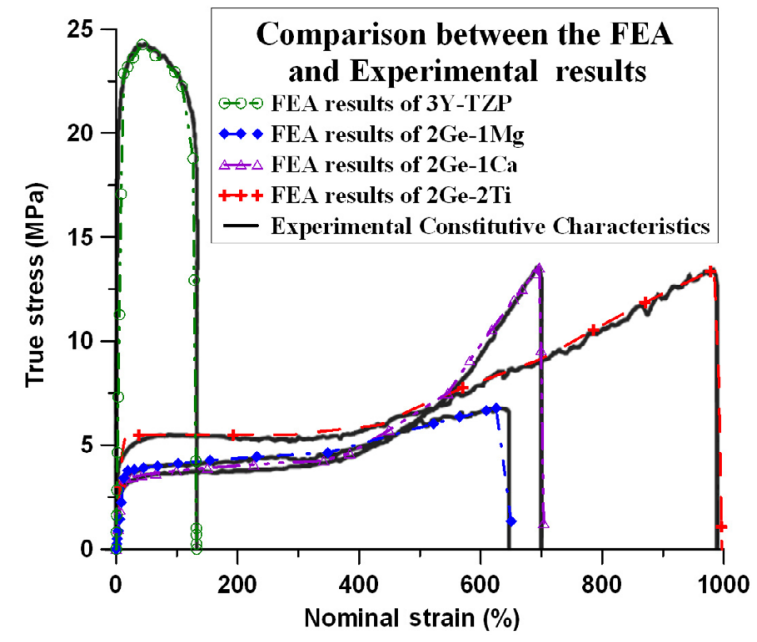

Fig. 7 Comparison between the FEA and experimental results for the stress-strain characteristics of 3Y-TZP and three co-doped materials

By comparing Fig. 8 with the corresponding experimental results in Fig. 2, the errors of the maximum nominal strain between the FEA and tensile tests can be calculated as: $3 \mathrm{Y}$-TZP, $0.26 \%$; $2 \mathrm{Ge}-$ $1 \mathrm{Mg}, 0.46 \%$; $2 \mathrm{Ge}-1 \mathrm{Ca}, 0.64 \%$; $2 \mathrm{Ge}-2 \mathrm{Ti}, 0.93 \%$. It can be seen that all of the errors are small enough to obtain accuracy. Moreover, the final deformed shapes, length, width, and thickness of the gauge section in the experimental samples agree well with the results of the FE simulation. These results show that the presented FEM is a suitable method by which to simulate the mechanical behavior of superplastic co-doped 3Y-TZP ceramics.

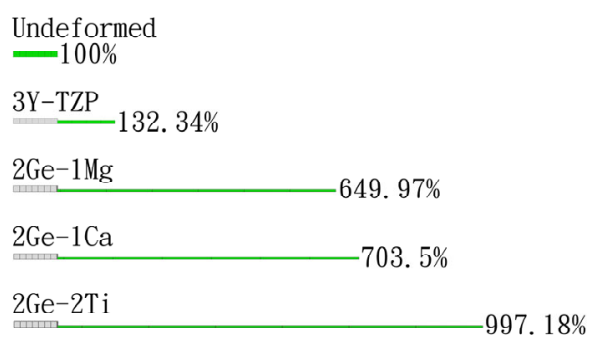

Fig. 8 Final deformed shapes in the FEA for 3Y-TZP and three co-doped compositions

The axial true stress contour defined by different colors and the values of nominal strain at different stages of deformation for $3 \mathrm{Y}-\mathrm{TZP}, 2 \mathrm{Ge}-1 \mathrm{Mg}$, $2 \mathrm{Ge}-1 \mathrm{Ca}$, and $2 \mathrm{Ge}-2 \mathrm{Ti}$ compositions are shown in Figs. 9-12, respectively, and they represent the deformation stages from the beginning of the analysis to the end. In these figures, the grade of axial true stress contour in Pascal $(\mathrm{Pa})$ is represented by different colors at the lower left corner. Using Fig. 12, for example, to explain other features, there are five samples in the figure, and the undeformed sample on the top indicates the initial condition of the analysis, in which the axial nominal strain and the axial true stress are both equal to zero, and the zero stress is located at the contour range from $-5.256 \times 10^{2} \mathrm{~Pa}$ to $1.344 \times 10^{6} \mathrm{~Pa}$. The second sample from the top of Fig. 12 indicates that the analysis is in the stage of plastic stretch with an axial nominal strain of $127.98 \%$, and the axial true stress of 5.5 MPa can be determined by corresponding to the $2 \mathrm{Ge}-2 \mathrm{Ti}$ stressstrain relationships for the FEA results shown in Fig. 7, and the stress locates at a contour range from $5.376 \times 10^{6} \mathrm{~Pa}$ to $6.720 \times 10^{6} \mathrm{~Pa}$. Similarly, the third, the fourth, and the fifth samples from the top of Fig. 12 reveal that the specimens are experiencing corresponding strain hardening deformation condition (the axial true stress is $7.75 \mathrm{MPa}$, and the axial nominal strain is $570.76 \%$ ), the maximum ultimate 
stress state (the axial true stress is $13.44 \mathrm{MPa}$, and the axial nominal strain is $984.14 \%$ ), and the ultimate fracture strain state (the axial true stress is $0 \mathrm{MPa}$, and the axial nominal strain is $997.18 \%$ ), respectively. One can interpret Figs. 9-11 in the same way corresponding to the results of 3Y-TZP, $2 \mathrm{Ge}-1 \mathrm{Mg}$, and $2 \mathrm{Ge}-1 \mathrm{Ca}$, respectively. Figs. 9-12 reveal that the axial stresses and strains are distributed uniformly in the model at every deformation stage. The reason for this was mentioned in Section 4 in which we described the problem type analyzed in the FEM as a uniform uniaxial loading acted on a uniform cross section of homogeneous and isotropic materials. Hence, the studied models became uniformly longer and thinner until the analysis stopped at a strain near the experimental ultimate fracture strain, and the axial stress varied with the axial strain, as shown in the relationships illustrated in Fig. 7. These results confirmed the reliability of the presented FEM.

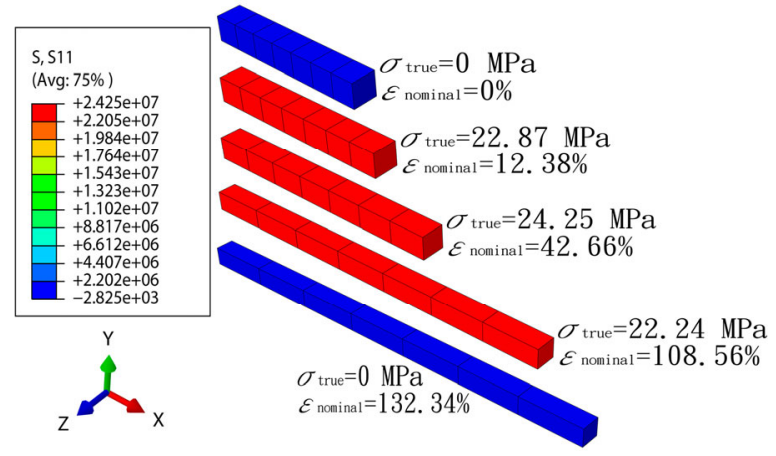

Fig. 9 Stress and strain history of the FEA at different stages of deformation for $3 Y$-TZP

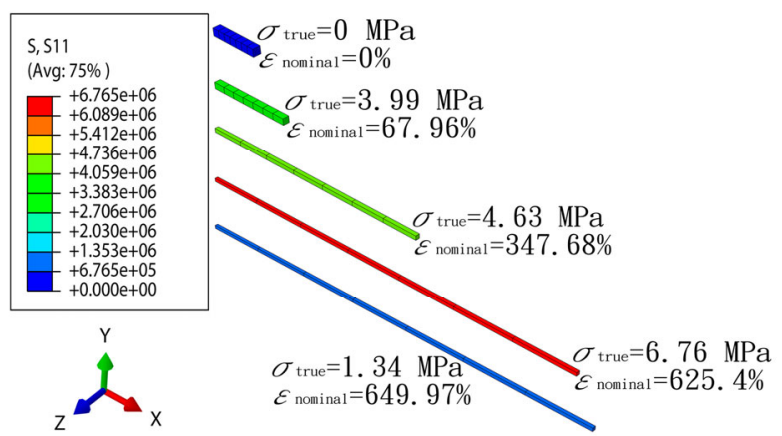

Fig. 10 Stress and strain history of the FEA at different stages of deformation for $2 \mathrm{Ge}-1 \mathrm{Mg}$

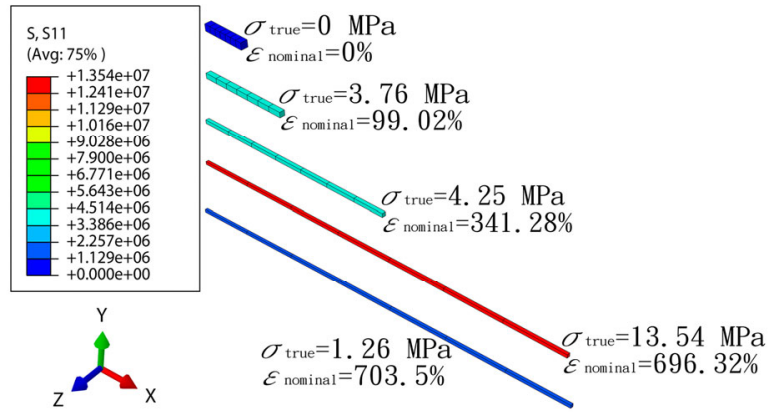

Fig. 11 Stress and strain history of the FEA at different stages of deformation for $2 \mathrm{Ge}-1 \mathrm{Ca}$

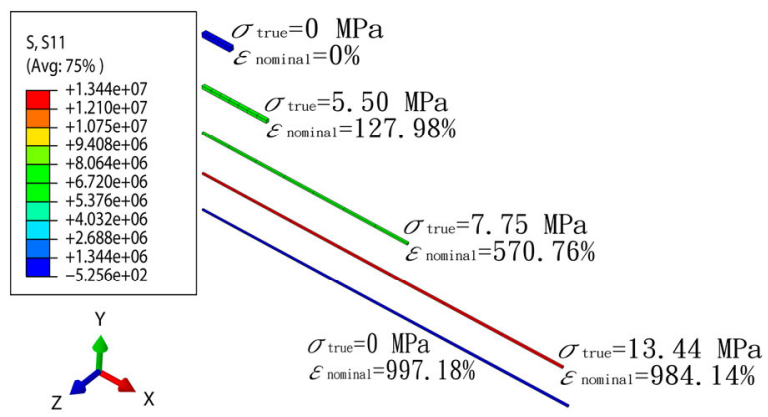

Fig. 12 Stress and strain history of the FEA at different stages of deformation for $2 \mathrm{Ge}-2 \mathrm{Ti}$

\section{Conclusions}

This paper presented a numerical FEM based on the theory of plasticity to simulate the uniaxial stress-strain progress of co-doped 3Y-TZP. The material model embedded in the FEM was an elasticplastic model, which simulated the elastic response using Hooke's law and the plastic strain hardening response using the flow rule associated with the von Mises yield criterion combined with the isotropic hardening rule. The simplified constitutive law used for the numerical simulations in Abaqus is based on piecewise linear connections at the turning points of different deformation stages on the experimental stress-strain curves. The presented FEM was verified with the tensile test experiments on superplastic $3 \mathrm{Y}$ TZP, $2 \mathrm{Ge}-1 \mathrm{Mg}, 2 \mathrm{Ge}-1 \mathrm{Ca}$, and $2 \mathrm{Ge}-2 \mathrm{Ti}$ ceramics performed by Sasaki et al. (2001).

During the analysis, in order to avoid the analysis aborting before reaching the experimental ultimate strain due to stress concentration and also to 
avoid an unreasonable peak elongation occurring at only a few elements on the junction of the outside clamping region and the middle gauge region of the bone samples, a geometry was constructed in the numerical FEM that only included the gauge region. The results showed that the stress-strain relationships analyzed by the presented FEM agreed well with the experimental data, and the errors for the maximum stress and strain were all less than $1 \%$ for the four compositions studied. Furthermore, the final deformed shapes (i.e., width and thickness) of the FEA were consistent with the results of tensile tests. These verifications confirm the reliability of the presented FEM, which can be used to analyze the mechanical behavior of materials such as superplastic co-doped 3Y-TZP ceramics. This paper gives a feasible model for simulating the constitutive characteristics of superplastic ceramics and to some degree makes up for the lack of numerical analysis available for this kind of material. In addition, this paper offers a model for analyzing applications related to the development of manufacturing process improvements, mechanical analyses, fracture predictions, and safe design specifications for superplastic ceramics.

\section{References}

Abu-Farha, F.K., Khraisheh, M.K., 2007. Analysis of superplastic deformation of AZ31 magnesium alloy. Advanced Engineering Materials, 9(9):777-783. http://dx.doi.org/10.1002/adem.200700155

Bieler, T.R., Mishra, R.S., Mukherjee, A.K., 1996. Superplasticity in hard-to-machine materials. Annual Review of Materials Science, 26(1):75-106. http://dx.doi.org/10.1146/annurev.ms.26.080196.000451

Chandra, N., 1988. Analysis of superplastic metal forming by a finite element method. International Journal for Numerical Methods in Engineering, 26(9):1925-1944. http://dx.doi.org/10.1002/nme.1620260904

Chen, W.F., Han, D.J., 2007. Plasticity for Structural Engineers. J. Ross Publishing, USA.

Chen, Y., Kibble, K., Hall, R., et al., 2001. Numerical analysis of superplastic blow forming of $\mathrm{Ti}-6 \mathrm{Al}-4 \mathrm{~V}$ alloys. Materials \& Design, 22(8):679-685. http://dx.doi.org/10.1016/S0261-3069(01)00009-7

Dassault Systèmes Corporation, 2014. SIMULIA Abaqus Analysis User's Manuals, Theory Manuals and Example Problems Manuals, Version 6.14. Dassault Systèmes Corporation, France.

Ding, X.D., Zbib, H.M., Hamilton, C.H., et al., 1995. On the optimization of superplastic blow-forming processes. Journal of Materials Engineering and Performance, 4(4):474-485
http://dx.doi.org/10.1007/BF02649309

Domínguez-Rodríguez, A., Gómez-García, D., 2010. Superplasticity in ceramics: applications and new trends. Key Engineering Materials, 423:3-13.

http://dx.doi.org/10.4028/www.scientific.net/KEM.423.3

El-Morsy, A., Akkus, N., Manabe, K., et al., 2001. Evaluation of superplastic material characteristics using multidome forming test. Materials Science Forum, 357-359: 587-592.

http://dx.doi.org/10.4028/www.scientific.net/MSF.357359.587

Garvie, R.C., Hannink, R.H., Pascoe, R.T., 1975. Ceramic steel. Nature, 258(5537):703-704. http://dx.doi.org/10.1038/258703a0

Giuliano, G., 2005. Simulation of instability during superplastic deformation using finite element method. Materials \& Design, 26(4):373-376.

http://dx.doi.org/10.1016/j.matdes.2004.06.005

Giuliano, G., 2006. Failure analysis in superplastic materials. International Journal of Machine Tools and Manufacture, 46(12-13):1604-1609.

http://dx.doi.org/10.1016/j.ijmachtools.2005.09.021

Hassan, N.M., Younan, M.Y., Salem, H.G., 2003. The finiteelement deformation modeling of superplastic Al-8090. JOM, 55(10):38-42.

http://dx.doi.org/10.1007/s11837-003-0174-z

Hsu, T.C., Chu, C.H., 1995. A finite-element analysis of sheet metal forming processes. Journal of Materials Processing Technology, 54(1-4):70-75. http://dx.doi.org/10.1016/0924-0136(95)01922-7

Hsu, T.C., Shien, I.R., 1997. Finite element modeling of sheet forming process with bending effects. Journal of Materials Processing Technology, 63(1-3):733-737. http://dx.doi.org/10.1016/S0924-0136(96)02715-X

Huh, H., Han, S.S., Lee, J.S., et al., 1995. Experimental verification of superplastic sheet-metal forming analysis by the finite-element method. Journal of Materials Processing Technology, 49(3-4):355-369. http://dx.doi.org/10.1016/0924-0136(94)01581-K

Jiménez-Melendo, M., Domínguez-Rodríguez, A., 1999. Like-metal superplasticity of fine-grained $\mathrm{Y}_{2} \mathrm{O}_{3}$-stabilized zirconia ceramics. Philosophical Magazine A, 79(7): 1591-1608. http://dx.doi.org/10.1080/01418619908210381

Jiménez-Melendo, M., Domínguez-Rodríguez, A., BravoLeón, A., 1998. Superplastic flow of fine-grained yttriastabilized zirconia polycrystals: constitutive equation and deformation mechanisms. Journal of the American Ceramic Society, 81(11):2761-2776. http://dx.doi.org/10.1111/j.1151-2916.1998.tb02695.x

Kim, Y.H., Hong, S.S., Lee, J.S., et al., 1996. Analysis of superplastic forming processes using a finite-element method. Journal of Materials Processing Technology, 62(1-3):90-99.

http://dx.doi.org/10.1016/0924-0136(95)02223-6

Lee, C.H., Kobayash, S., 1973. New solutions to rigid-plastic 
deformation problems using a matrix method. Journal of Manufacturing Science and Engineering, 95(3):865-873.

Li, G.Y., Tan, M.J., Liew, K.M., 2004. The finite-element deformation modeling of superplastic A1-8090. Journal of Materials Processing Technology, 150(1-2):76-83. http://dx.doi.org/10.1016/j.jmatprotec.2004.01.023

Liew, K.M., Tan, H., Tan, M.J., 2003. Finite element modeling of superplastic sheet metal forming for cavity sensitive materials. Journal of Engineering Materials and Technology, 125(3):256-259. http://dx.doi.org/10.1115/1.1584491

Lin, J., 2003. Selection of material models for predicting necking in superplastic forming. International Journal of Plasticity, 19(4):469-481. http://dx.doi.org/10.1016/S0749-6419(01)00059-6

Nazzal, M.A., Khraisheh, M.K., 2008. Impact of selective grain refinement on superplastic deformation: finite element analysis. Journal of Materials Engineering and Performance, 17(2):163-167. http://dx.doi.org/10.1007/s11665-007-9180-6

Nazzal, M.A., Khraisheh, M.K., Darras, B.M., 2004. Finite element modeling and optimization of superplastic forming using variable strain rate approach. Journal of Materials Engineering and Performance, 13(6):691-699. http://dx.doi.org/10.1361/10599490421321

Nazzal, M.A., Abu-Farha, F., Curtis, R., 2011. Finite element simulations for investigating the effects of specimen geometry in superplastic tensile tests. Journal of Materials Engineering and Performance, 20(6):865-876. http://dx.doi.org/10.1007/s11665-010-9727-9

Sasaki, K., Nakano, M., Mimurada, J., et al., 2001. Strain hardening in superplastic co-doped yttria-stabilized tetragonal-zirconia polycrystals. Journal of the American Ceramic Society, 84(12):2981-2986. http://dx.doi.org/10.1111/j.1151-2916.2001.tb01124.x

Tao, J., Keavey, M.A., 2004. Finite element simulation for superplastic forming using a non-Newtonian viscous thick section element. Journal of Materials Processing Technology, 147(1):111-120. http://dx.doi.org/10.1016/j.jmatprotec.2003.12.004

Wakai, F., Sakaguchi, S., Matsuno, Y., 1986. Superplasticity of yttria-stabilized tetragonal $\mathrm{ZrO}_{2}$ polycrystals. $A d$ vanced Ceramic Materials, 1(3):259-263. http://dx.doi.org/10.1111/j.1551-2916.1986.tb00026.x

Wakai, F., Kondo, N., Shinoda, Y., 1999. Ceramics superplasticity. Current Opinion in Solid State and Materials Science, 4(5):461-465.
http://dx.doi.org/10.1016/S1359-0286(99)00053-4

Wang, N.M., Budiansky, B., 1978. Analysis of sheet metal stamping by a finite-element method. Journal of Applied Mechanics, 45(1):73-82. http://dx.doi.org/10.1115/1.3424276

Yenihayat, O.F., Mimaroglu, A., Unal, H., 2005. Modelling and tracing the super plastic deformation process of 7075 aluminium alloy sheet: use of finite element technique. Materials \& Design, 26(1):73-78. http://dx.doi.org/10.1016/j.matdes.2004.03.013

Zienkiewicz, O.C., Godbole, P.N., 1974. Flow of plastic and visco-plastic solids with special reference to extrusion and forming processes. International Journal for Numerical Methods in Engineering, 8(1):1-16. http://dx.doi.org/10.1002/nme.1620080102

\section{中文概要}

题 目: 超塑性 Y-TZP 基陶瓷之有限元分析

目的: 通过调整非常精细的颗粒, 四方晶氧化锆多晶 (TZP) 在室温下保持稳态四方相, 并且具有优 异的塑性。然而, 当材料变形时, 我们必须对 超塑性陶瓷在机械应力分布和断裂机制方面有 更多的理解。

创新点: 1. 通过材料弹塑性模型; 2. 使用胡克定律、塑 性应变硬化及 von Mises 降伏准则；3. 结合等向 性硬化规则及相关联的流动规则。

方 法: 1. 开发一个高温超塑性材料在不同应变率拉伸 条件下具备不同应力-应变关系的组成律模型及 有限元分析模型; 2. 通过有限元法仿真模拟与 实验结果比对; 3. 验证所提方法的可行性和精 确性。

结 论: 1. 有限元仿真模拟的应力-应变关系与实验数据 吻合较好, 对于所研究的四种组合物, 最大应 力和应变的误差均小于 $1 \%$ 。2. 有限元仿真模拟 的最终变形形状 (宽度和厚度) 与拉伸试验的 结果一致; 这些验证证实了所提有限元分析模 型的可靠性。

关键词：有限元分析；Y-TZP 基陶瓷；超塑性 